\title{
Prevalence and Associated Diseases of Seborrheic Skin in Adults
}

\author{
Natalia Kirsten (D) \\ Nicole Mohr (D) \\ Aminah Alhumam ${ }^{1,2}$ \\ Matthias Augustin (1) \\ 'Institute for Health Services Research in \\ Dermatology and Nursing (IVDP), \\ University Medical Center Hamburg- \\ Eppendorf (UKE), Hamburg, Germany; \\ ${ }^{2}$ Department of Dermatology, College of \\ Medicine, King Faisal University, Hofuf, Al \\ Ahsa, Saudi Arabia
}

Correspondence: Natalia Kirsten Institute for Health Services Research in Dermatology and Nursing (IVDP), University Medical Center HamburgEppendorf (UKE), 20246 Hamburg, Germany

Tel +49-40-74l 0-55428

Fax +49-40-7410-5348

Email n.kirsten@uke.de
Background: Seborrhea is a skin condition characterized by abundant production of sebum associated with typical dermatological conditions such as rosacea and acne. Little is known about the prevalence of seborrhea and the frequency of concurrent skin diseases in the general population.

Objective: To investigate the epidemiology and comorbidity of seborrhea in the adolescent and adult working population.

Methods: In large-scale examinations by dermatologists in 343 German companies, the seborrheic skin type and the occurrence of skin findings were documented electronically. Odds ratios (OR) and their 95\% confidence intervals (95\% CI) of further skin diseases were computed. Logistic regression analyses were conducted for each disease using seborrhea as dependent variable.

Results: A total of 48,630 employees were examined. About $6.0 \%$ showed seborrhea $(6.6 \%$ in men, $5.4 \%$ in women). Seborrhea strongly predicted acne (OR 3.59; CI 3.18-4.05), trichilemmal cysts (OR 1.99; CI 1.25-3.18) and rosacea (OR 1.45; CI 1.17-1.81). Regression analyses controlling for age, gender and phototype confirmed significant associations of seborrhea with acne and rosacea.

Conclusion: Only a minor proportion of the working population shows meaningful seborrheic skin. However, this condition predicts distinct skin diseases and thus needs attention, in particular, with respect to consulting and secondary prevention.

Keywords: seborrhea, seborrheic skin, epidemiology, comorbidities

\section{Introduction}

Seborrhea is characterized by an overactivity of sebaceous glands, resulting in an excessive secretion of sebum. ${ }^{1,2}$ Seborrhea is also used as a synonym for seborrheic dermatitis, a skin disorder which is characterized by inflammatory scaling rush in seborrheic areas of the body. In this publication, the term seborrhea is used to describe the skin condition characterized by an oily skin due to hyperproduction of sebum without inflammatory reaction. Seborrhea has been shown to be a major pathogenetic factor for acne. ${ }^{3}$ Moreover, several other conditions like polycystic ovary syndrome ${ }^{4,5}$ or pityriasis versicolor ${ }^{6}$ are associated with increased sebum secretion. Seborrhea is more common in colored skin and in male people. ${ }^{7}$ Especially androgens seem to have a regulatory role in sebum secretion. ${ }^{8,9}$ The skin surface lipid film, derived by sebaceous glands, is an important part of skin barrier. ${ }^{10}$ Any alteration of lipid film of the skin can contribute to manifestation of common inflammatory skin diseases like acne vulgaris, rosacea or seborrheic dermatitis. ${ }^{10}$ Condition-adapted skin care has been shown to improve skin condition and patient well-being by restoring the disturbed 
barrier function and by re-establishing well-being and quality of life. ${ }^{11}$ Moreover, skin care adapted to the specific needs of the individuals can support the prevention of exacerbating skin inflammation and chronification.

In spite of the fact that seborrhea is a common condition, especially in young people, little is known about the population-based prevalence in Germany. For this, the objective of the current study was to gain robust data for the working-age population on the prevalence and comorbidity of dry skin across Germany. The research questions were as follows:

1. Which is the prevalence of seborrhea in the German adult population?

2. Which dermatologic comorbidities are associated with seborrhea?

3. Which comedication profile is associated with seborrhea?

\section{Materials and Methods Centers and People}

Dermatological whole-body exams were performed in 48,630 employed persons by dermatologists during voluntary company-based skin screenings in 343 German companies as described previously. ${ }^{12,13}$ To reduce selection bias, the screenings were conducted during the working hours, and every employee was asked to participate. Validity and sensitivity of the procedures have been shown previously. ${ }^{12,13}$

All procedures performed were in accordance with the ethical standards of the institutional and/or national research committee and with the 1964 Helsinki declaration and its later amendments or comparable ethical standards. The study has received a granted ethics vote from the ethics committee of the Medical Association Hamburg. All subjects included in the study have signed an informed consent.

\section{Assessments}

The whole-body exams were conducted by trained dermatologists and recorded in an electronic database by a research assistant. Seborrhea was evaluated both clinically and by interviewing the individual. The assessment of seborrhea was based on the validated six-item skin oiliness scale (SOS). ${ }^{14}$ Seborrhea was considered prevalent when alternatively meeting the following criteria as proposed by Baumann et al: a) Three hours after washing the face it appears shiny with reflection of bright light, b) the facial skin of the person is often or always oily at the latest one hour after washing the face on the T-zone, c) the person has clogged pores and b) the skin must be washed at least twice a day for seborrhea. Every other condition of the skin found by the dermatologist was recorded. Skin type was categorized according to the phototypes I-IV by Fitzpatrick. ${ }^{15}$ Furthermore, medical history, comorbidity and systemic comedication were obtained.

\section{Statistics}

Statistical analyses were performed using SPSS for Windows 23.0 (IBM, Armonk, New York, US.). Seborrhea and further conditions were assessed as dichotomous variables and point prevalence rates of further dermatological conditions were calculated. Subgroup analyses were conducted to compare the prevalence rates between people with and without seborrhea. Odds ratios (OR) and their 95\% confidence intervals (95\% CI) were computed indicating the chance of people with seborrhea to also have the diagnosis of any further skin disease. To account for the influence of age, gender and skin phototype, logistic regression analyses were conducted for each disease using seborrhea as dependent variable.

\section{Results}

\section{Centers and People}

In $n=343$ German companies, a total of $n=48,630$ persons were examined. The mean age was $43.2 \pm 11.4$ years, $52.8 \%(\mathrm{n}=25,674)$ were male. In total, $\mathrm{n}=2932$ persons (6.0\%) had seborrheic skin (men: 1700; 6.6\%, women: $1232 ; 5.4 \% ; \mathrm{p}<0.001)$. Prevalence decreased by age (Figure 1). The prevalence of seborrheic skin also differed between skin phototypes: Skin type I $(n=4235)$ : $6.6 \%$, skin type II $(\mathrm{n}=36,542): 6.2 \%$, skin type III $(\mathrm{n}=7357)$ : $5.0 \%$ skin type IV $(\mathrm{n}=264): 8.7 \%$. There was a significant difference between skin type III and IV $(p=0.007)$ but not between skin type I, II, III combined (6.2\%) vs IV (8.7\%).

In group comparisons, a significantly higher rate of comorbidity among participants with seborrhea was found for the following dermatological conditions (Table 1): acne (OR 3.59; CI 3.18-4.05), trichilemmal cysts (OR 1.99; CI 1.25-3.18), seborrheic eczema (OR 1.94; CI 1.65-2.27), folliculitis (OR 1.74; CI 1.54-1.97), pyodermia (OR 1.69; CI 1.20-2.37), hypertrophic sebaceous glands (OR 1.66; CI 1.40-1.97), rosacea (OR 1.45; CI 1.17-1.81) and verruca vulgaris (OR 1.37; CI 1.01-1.86). Significantly less common in people with 


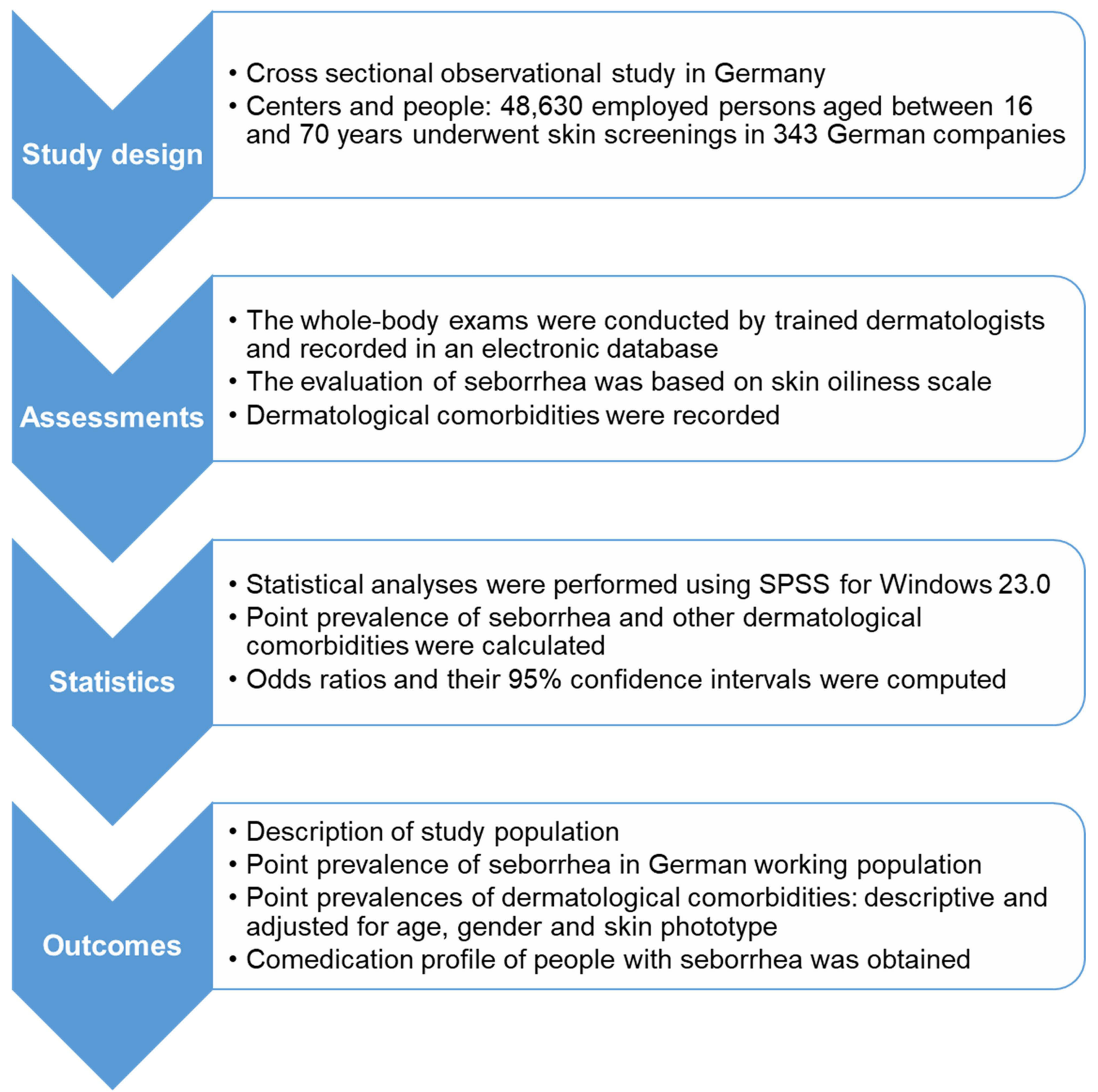

Figure I Flowchart of the materials and methods.

seborrhea were atopic eczema (OR 0.51; CI 0.33-0.78), other inflammatory skin diseases excluding rosacea (OR 0.67; CI 0.48-0.94), lentigo solaris (OR 0.69; CI 0.64-0.75) and atopic diathesis (OR 0.91; CI 0.83-0.99).

\section{Dermatologic Conditions Predicted by Seborrhea}

In the regression analyses controlling for age, gender and skin phototype IV, seborrhea was a significant predictor for: acne (3.45; CI 3.03-3.91), contact dermatitis (OR 2.15; CI 1.33-3.48), trichilemmal cysts (OR 1.98; CI 1.24-3.17), seborrheic eczema (OR 1.87; CI 1.59-2.20), folliculitis (OR 1.62; CI 1.43-1.84), pyodermia (OR 1.55; CI 1.10-2.19), rosacea (OR 1.54; CI 1.23-1.92), other benign non-inflammatory skin conditions (OR 1.52; CI 1.16-2.00) and verruca vulgaris (OR 1.38; CI 1.02-1.87) (Table 2).

By contrast, seborrhea was a negative predictor for atopic eczema (OR 0.50; CI 0.32-0.76), other 
Table I Frequency of Skin Conditions in People with versus without Seborrheic Skin $(n=48,630)$

\begin{tabular}{|c|c|c|c|c|c|c|c|c|}
\hline & & \multicolumn{2}{|c|}{$\begin{array}{l}\text { Total } \\
n=48,630\end{array}$} & \multicolumn{2}{|c|}{$\begin{array}{l}\text { Seborrhea } \\
n=2932\end{array}$} & \multicolumn{2}{|c|}{$\begin{array}{l}\text { No } \\
\text { Seborrhea } \\
n=45,698\end{array}$} & \multirow{2}{*}{$\begin{array}{l}\text { OR (Occurrence Among } \\
\text { People with Seborrhea) } \\
\text { OR (95\% Cl) }\end{array}$} \\
\hline & & $\mathbf{n}$ & $\%$ & $\mathbf{n}$ & $\%$ & $\mathbf{n}$ & $\%$ & \\
\hline & Atopic diathesis & 12,273 & 25.24 & 689 & 23.50 & 11,584 & 25.35 & $0.905(0.828-0.988)$ \\
\hline \multirow[t]{2}{*}{ Bacterial infections } & Folliculitis & 3195 & 6.57 & 308 & 10.50 & 2887 & 6.32 & 1.741 (1.538-1.970) \\
\hline & Pyodermia & 381 & 0.78 & 37 & 1.26 & 344 & 0.75 & $1.685(1.198-2.370)$ \\
\hline \multirow{5}{*}{$\begin{array}{l}\text { Other benign non- } \\
\text { inflammatory skin } \\
\text { conditions }\end{array}$} & Lentigo solaris & 24,357 & 50.09 & 1219 & 41.58 & 23,138 & 50.63 & $0.694(0.643-0.748)$ \\
\hline & Fibroma & 15,755 & 32.40 & 1050 & 35.81 & 14,705 & 32.18 & I.I76 (I.088-I.27I) \\
\hline & Seborrheic keratosis & $|2,23|$ & 25.15 & 854 & 29.13 & II,377 & 24.90 & $1.240(1.142-1.346)$ \\
\hline & $\begin{array}{l}\text { Hypertrophic sebaceous } \\
\text { gland }\end{array}$ & 1590 & 3.27 & 150 & 5.12 & 1440 & 3.15 & 1.657 (1.395-1.969) \\
\hline & $\begin{array}{l}\text { Other benign non- } \\
\text { inflammatory skin } \\
\text { conditions }\end{array}$ & 668 & 1.37 & 59 & 2.01 & 609 & 1.33 & $1.520(1.161-1.992)$ \\
\hline \multirow[t]{3}{*}{ Cysts } & Epidermal cysts & 662 & 1.36 & 47 & 1.60 & 615 & 1.35 & $1.194(0.886-1.610)$ \\
\hline & Trichilemmal cysts & 177 & 0.36 & 20 & 0.68 & 157 & 0.34 & $1.992(1.249-3.178)$ \\
\hline & Other skin cysts & 123 & 0.25 & 5 & 0.17 & 118 & 0.26 & $0.660(0.269-1.616)$ \\
\hline \multirow[t]{6}{*}{ Inflammatory skin diseases } & Acne & 2055 & 4.23 & 357 & 12.18 & 1698 & 3.72 & $3.593(3.184-4.054)$ \\
\hline & Seborrheic dermatitis & 1636 & 3.36 & 176 & 6.00 & 1460 & 3.19 & 1.935 (1.647-2.273) \\
\hline & Rosacea & 1052 & 2.16 & 89 & 3.04 & 963 & 2.11 & $1.454(1.167-1.813)$ \\
\hline & Atopic dermatitis & 694 & 1.43 & 22 & 0.75 & 672 & 1.47 & $0.507(0.33 \mathrm{I}-0.776)$ \\
\hline & Psoriasis & 1005 & 2.07 & 68 & 2.32 & 937 & 2.05 & I.I34 (0.884-I.455) \\
\hline & $\begin{array}{l}\text { Other inflammatory skin } \\
\text { diseases }\end{array}$ & 843 & 1.73 & 35 & 1.19 & 808 & 1.77 & $0.671(0.478-0.943)$ \\
\hline Fungal skin infections & Tinea corporis & 229 & 0.47 & 16 & 0.55 & 213 & 0.47 & $1.172(0.704-1.950)$ \\
\hline \multirow[t]{2}{*}{ Viral skin infections } & Verruca vulgaris & 572 & 1.18 & 46 & 1.57 & 526 & 1.15 & $1.369(1.010-1.855)$ \\
\hline & Herpes labialis & 206 & 0.42 & 8 & 0.27 & 198 & 0.43 & $0.629(0.310-1.276)$ \\
\hline
\end{tabular}

Abbreviations: OR, odds ratio; $\mathrm{Cl}$, confidence interval.

inflammatory skin diseases (OR 0.67; CI 0.47-0.94) and lentigo solaris (OR 0.71; CI 0.66-0.77).

\section{Comedication Profile in People with Seborrhea}

People with seborrhea used more frequently steroids (OR 1.59; CI 1.12-2.09). Less commonly used were hormones (OR 0.82; CI 0.74-0.91) and other drugs (OR 0.90; CI 0.81-0.99; Table 3). Stratified by gender, there was no difference for hormone intake as comedication between people with versus without seborrhea. Male people with seborrhea more frequently used steroids as comedication (OR 1.76; CI 1.21-2.55). Female people with seborrhea more frequently used antidiabetics (OR 2.19; CI 1.433.37) and psychotropic drugs (OR 1.68; CI 1.10-2.56) compared to those without seborrhea.

\section{Discussion}

The aim of the current study was to address the prevalence of seborrhea as a typical dysfunctional skin pattern in the 
Table 2 Odds Ratio (OR) of the Occurrence of Different Skin Conditions Among People with Seborrhea, Controlling for Age and Gender and Skin Phototype IV $(n=48,630)$

\begin{tabular}{|c|c|c|}
\hline Skin Disease & OR & $\begin{array}{c}95 \% \mathrm{Cl} \text { of } \\
\text { OR }\end{array}$ \\
\hline Folliculitis & 1.624 & $1.432-1.843$ \\
\hline Pyodermia & 1.554 & $1.103-2.189$ \\
\hline Lentigo solaris & 0.709 & $0.655-0.767$ \\
\hline Fibroma & 1.220 & $1.126-1.322$ \\
\hline Seborrheic keratosis & $1.46 \mathrm{I}$ & $1.329-1.605$ \\
\hline Hypertrophic sebaceous gland & 1.687 & $1.417-2.009$ \\
\hline $\begin{array}{l}\text { Other benign non-inflammatory skin } \\
\text { conditions }\end{array}$ & 1.523 & $1.162-1.995$ \\
\hline Epidermoid cysts & 1.209 & $0.896-1.632$ \\
\hline Trichilemmal cysts & 1.984 & $1.243-3.167$ \\
\hline Other cysts & 0.674 & $0.275-1.652$ \\
\hline Acne & 3.445 & $3.033-3.913$ \\
\hline Seborrheic eczema & 1.870 & $\mid .589-2.20 \mathrm{I}$ \\
\hline Rosacea & 1.537 & $1.229-1.92 \mid$ \\
\hline Other inflammatory skin diseases & 0.671 & $0.478-0.944$ \\
\hline Atopic dermatitis & 0.494 & $0.323-0.758$ \\
\hline Psoriasis & 0.379 & $0.094-1.525$ \\
\hline Contact dermatitis & 2.149 & I.328-3.477 \\
\hline Pityriasis versicolor & 1.141 & $0.781-1.669$ \\
\hline Tinea corporis & 1.088 & $0.643-1.84 \mid$ \\
\hline Verruca vulgaris & $\mathrm{I} .38 \mathrm{I}$ & $|.019-1.87|$ \\
\hline
\end{tabular}

Abbreviation: $\mathrm{Cl}$, confidence interval.

normal adult population. Furthermore, potential predictors were to be identified. Investigations were conducted during large-scale skin examinations including a large and largely representative proportion of the adult working population. No technology-based evaluation to detect seborrhea was possible to perform. This is one of the limitations. However, all exams were conducted by trained dermatologists with considerable experience in clinical dermatological examinations who used a clinical scoring system. Within these limitations, the prevalence of seborrhea of $6 \%$ can be assumed as robust. It corresponds to numbers reported in smaller and more selective cohorts. ${ }^{16,17}$
The skin-related comorbidity and the triggering factors determined, support the experience from clinical care and from the few studies published, ${ }^{3,18,19}$ suggesting that acne, seborrheic eczema, folliculitis and rosacea are associated with seborrhea.

Increased sebogenesis is crucial for the pathogenesis of acne and predisposes the skin to deregulated inflammatory reactions. The quantitative as well as the qualitative differences in sebum composition play a role here. ${ }^{18,20,21}$ This also appears comprehensible, since the increased sebum production alters the microenvironment, favoring colonization with Propionibacterium acnes. ${ }^{22,23}$ This leads to dysbiosis followed by an inflammatory reaction. The association found between seborrhea and acne seems plausible. It must be assumed that seborrhea precedes acne vulgaris and that appropriate skin care could stop the progress into an inflammatory condition.

In most cases, folliculitis is caused by Staphylococcus aureus. ${ }^{24}$ Here, too, it is conceivable that seborrhea favors the proliferation of Staphylococcus aureus and, similar to acne vulgaris, favors the disease.

Any change in the lipid film can lead to the manifestation of inflammatory skin disease. ${ }^{18}$ This may confirm the observation in the current study that people with seborrhea were more likely to develop rosacea. ${ }^{25}$ We also observed that people with seborrhea used more frequently systemic glucocorticosteroids reported to have a strong enhancing effect on the regulation of the pilosebaceous unit. Recent evidence suggests that steroid-induced inflammation may contribute to the development of acne by activating toll-like receptor $2{ }^{26}$ It remains unclear whether patients treated with systemic steroids are more likely to develop seborrhea or whether seborrhea may be associated with other inflammatory diseases requiring steroid therapy. Further research is needed to better understand these relationships.

Our data show a significantly higher prevalence of seborrhea in skin phototype IV compared to type III. It was reported about differences in sebum level in different ethnic population groups. ${ }^{27}$ Although this subgroup is small $(\mathrm{n}=264)$, such finding should be further explored.

Overall, the current study indicates that a small but relevant part of the general population suffers from seborrhea and associated diseases. Timely initiated adapted skin care could prevent the manifestation of inflammatory skin diseases and thus improve the persons' quality of life.

\section{Conclusion}

Our study shows that seborrhea is a non-negligible skin condition in the German working population especially in 
Table 3 Frequency of Comedications in People with versus without Seborrhea

\begin{tabular}{|c|c|c|c|c|c|c|c|}
\hline \multirow[b]{2}{*}{ Drug } & \multicolumn{2}{|c|}{$\begin{array}{c}\text { Total } \\
(n=48,630)\end{array}$} & \multicolumn{2}{|c|}{$\begin{array}{c}\text { No Seborrhea } \\
(n=45,698)\end{array}$} & \multicolumn{2}{|c|}{$\begin{array}{l}\text { Seborrhea } \\
(n=2932)\end{array}$} & \multirow{2}{*}{ 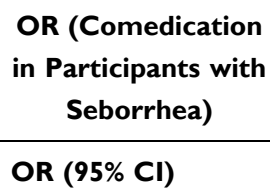 } \\
\hline & $\mathbf{n}$ & $\%$ & $\mathbf{n}$ & $\%$ & $\mathbf{n}$ & $\%$ & \\
\hline Analgetics & 1013 & 2.08 & 966 & 2.11 & 47 & 1.60 & $0.754(0.562-1.012)$ \\
\hline Antibiotics & 194 & 0.40 & 185 & 0.40 & 9 & 0.31 & $0.757(0.388-1.480)$ \\
\hline Antidiabetics & 664 & 1.37 & 617 & 1.35 & 47 & 1.60 & $1.190(0.883-1.605)$ \\
\hline $\begin{array}{l}\text { Cardiovascular } \\
\text { drugs }\end{array}$ & 5167 & 10.63 & 4838 & 10.59 & 329 & 11.22 & I.067 (0.948-I.202) \\
\hline Hormones & 9358 & 19.24 & 8874 & 19.42 & 484 & $|6.5|$ & $0.820(0.742-0.907)$ \\
\hline Psychotropic drugs & 439 & 0.90 & 403 & 0.88 & 36 & 1.23 & $1.397(0.991-1.969)$ \\
\hline Hypnotics & 58 & 0.12 & 54 & 0.12 & 4 & 0.14 & $1.155(0.418-3.191)$ \\
\hline Steroids & 631 & 1.30 & 573 & 1.25 & 58 & 1.98 & $1.589(1.210-2.088)$ \\
\hline Other & 8035 & 16.52 & 7590 & 16.61 & 445 & 15.18 & $0.898(0.810-0.997)$ \\
\hline
\end{tabular}

Abbreviations: $\mathrm{OR}$, odds ratio; $\mathrm{Cl}$, confidence interval.

darker skin types. Seborrhea can promote other inflammatory skin diseases; therefore, this skin condition should not be neglected in daily practice.

\section{Data Sharing Statement}

The data that support the findings of this study are available on request from the corresponding author. The data are not publicly available due to restrictions, eg, their containing information that could compromise the privacy of research participants.

\section{Acknowledgments}

We thank Heigel $\mathrm{GmbH}$ for providing the data. The authors thank the Scientific Communication Team of the IVDP, in particular Sara Tiedemann and Mario Gehoff, for copy editing.

\section{Author Contributions}

All authors contributed to data analysis, drafting or revising the article, gave final approval of the version to be published, agreed to the submitted journal, and agreed to be accountable for all aspects of the work.

\section{Funding}

There is no funding to report.

\section{Disclosure}

The authors declare no conflicts of interest.

\section{References}

1. Burton JL, Pye RJ. Seborrhoea is not a feature of seborrhoeic dermatitis. Br Med J (Clin Res Ed). 1983;286(6372):1169-1170. doi:10.1136/bmj.286.6372.1169

2. Braun-Falco O. Letter: definition of a sebostatic and seborrheic patient. Hautarzt. 1975;26(10):557.

3. Youn SW. The role of facial sebum secretion in acne pathogenesis: facts and controversies. Clin Dermatol. 2010;28(1):8-11. doi:10.1016/j.clindermatol.2009.03.011

4. Feng JG, Guo Y, Ma LA, Xing J, Sun RF, Zhu W. Prevalence of dermatologic manifestations and metabolic biomarkers in women with polycystic ovary syndrome in north China. $J$ Cosmet Dermatol. 2017;17(3):511-517. doi:10.1111/jocd.12387

5. Keen MA, Shah IH, Sheikh G. Cutaneous manifestations of polycystic ovary syndrome: a Cross-Sectional Clinical Study. Indian Dermatol Online J. 2017;8(2):104-110. doi:10.4103/2229-5178.202275

6. Difonzo EM, Faggi E. Skin diseases associated with Malassezia species in humans. Clinical features and diagnostic criteria. Parassitologia. 2008;50(1-2):69-71.

7. Alexis AF, Sergay AB, Taylor SC. Common dermatologic disorders in skin of color: a comparative practice survey. Cutis. 2007;80 (5):387-394.

8. Sakuma TH, Maibach HI. Oily skin: an overview. Skin Pharmacol Physiol. 2012;25(5):227-235. doi:10.1159/000338978

9. Zouboulis CC, Baron JM, Böhm M, et al. Frontiers in sebaceous gland biology and pathology. Exp Dermatol. 2008;17(6):542-551. doi:10.1111/j.1600-0625.2008.00725.x

10. Rippke F, Schreiner V, Schwanitz HJ. The acidic milieu of the horny layer: new findings on the physiology and pathophysiology of skin pH. Am J Clin Dermatol. 2002;3(4):261-672. doi:10.2165/00128071200203040-00004

11. Augustin M, Schäfer I, Rabini S, Lee-Seifert C, Radtke M, Rustenbach SJ. Assessing the value of supportive skin care: development and validation of an instrument for evaluating patient-relevant benefit. Dermatology. 2009;218(3):255-259. doi:10.1159/000195174

12. Augustin M, Herberger K, Hintzen S, Heigel H, Franzke N, Schäfer I. Prevalence of skin lesions and need for treatment in a Cohort of 90 880 workers. Br J Dermatol. 2011;165(4):865-873. doi:10.1111/ j.1365-2133.2011.10436.x 
13. Schaefer I, Rustenbach SJ, Zimmer L, Augustin M. Prevalence of skin diseases in a Cohort of 48,665 employees in Germany. Dermatology. 2008;217(2):169-172. doi:10.1159/000136656

14. Baumann LS, Penfield RD, Clarke JL, Duque DK. A validated questionnaire for quantifying skin oiliness. $J$ Cosmetics Dermatol Sci Appl. 2014;4(2):78-84. doi:10.4236/jcdsa.2014.42012

15. Fitzpatrick TB. The validity and practicality of sun-reactive skin types I through VI. Arch Dermatol. 1988;124(6):869-871. doi:10.1001/archderm.1988.01670060015008

16. Naldi L. Seborrhoeic dermatitis. BMJ Clin Evid. 2010;2010:1713.

17. Bukvić Mokos Z, Kralj M, Basta-Juzbašić A, Lakoš Jukić I. Seborrheic dermatitis: an update. Acta Dermatovenerol Croat. 2012;20(2):98-104.

18. Shi VY, Leo M, Hassoun L, Chahal DS, Maibach HI, Sivamani RK. Role of sebaceous glands in inflammatory dermatoses. $J$ Am Acad Dermatol. 2015;73(5):856-863. doi:10.1016/j.jaad.2015.08.015

19. Park SY, Kwon HH, Min S, Yoon JY, Suh DH. Clinical manifestation and associated factors of seborrheic dermatitis in Korea. Eur J Dermatol. 2016;26(2):173-176. doi:10.1684/ejd.2015.2706

20. Zouboulis CC, Eady A, Philpott M, et al. What is the pathogenesis of acne? Exp Dermatol. 2005;14(2):143-152. doi:10.1111/j.09066705.2005.0285a.x

21. Zouboulis CC, Jourdan E, Picardo M. Acne is an inflammatory disease and alterations of sebum composition initiate acne lesions. $J$ Eur Acad Dermatol Venereol. 2014;28(5):527-532. doi:10.1111/jdv.12298
22. Moradi Tuchayi S, Makrantonaki E, Ganceviciene R, Dessinioti C, Feldman SR, Zouboulis CC. Acne vulgaris. Nat Rev Dis Primers. 2015;1:15029.

23. Dréno B. What is new in the pathophysiology of acne, an overview. J Eur Acad Dermatol Venereol. 2017;31(Suppl 5):8-12. doi:10.1111/ jdv. 14374

24. Laureano AC, Schwartz RA, Cohen PJ. Facial bacterial infections: folliculitis. Clin Dermatol. 2014;32(6):711-714. doi:10.1016/j. clindermatol.2014.02.009

25. Yoon JS, Nishifuji K, Ishioroshi S, Ide K, Iwasaki T. Skin lipid profiling in normal and seborrhoeic shih tzu dogs. Vet Dermatol. 2013;24(1):84-89.e21-2. doi:10.1111/j.1365-3164.2012.01102.x

26. Lee SE, Kim J-M, Jeong M-K, Zouboulis CC, Lee SH. 11ßhydroxysteroid dehydrogenase type 1 is expressed in human sebaceous glands and regulates glucocorticoid-induced lipid synthesis and toll-like receptor 2 expression in SZ95 sebocytes. Br J Dermatol. 2013;168(1):47-55. doi:10.1111/bjd.12009

27. Pouradier F, Liu C, Wares J, et al. The worldwide diversity of scalp seborrhoea, as daily experienced by seven human ethnic groups. Int J Cosmet Sci. 2017;39(6):629-636. doi:10.1111/ics.12425
Clinical Epidemiology

\section{Publish your work in this journal}

Clinical Epidemiology is an international, peer-reviewed, open access, online journal focusing on disease and drug epidemiology, identification of risk factors and screening procedures to develop optimal preventative initiatives and programs. Specific topics include: diagnosis, prognosis, treatment, screening, prevention, risk factor modification,

Submit your manuscript here: https://www.dovepress.com/clinical-epidemiology-journal

\section{Dovepress}

systematic reviews, risk \& safety of medical interventions, epidemiology \& biostatistical methods, and evaluation of guidelines, translational medicine, health policies \& economic evaluations. The manuscript management system is completely online and includes a very quick and fair peer-review system, which is all easy to use. 